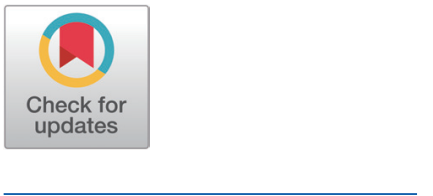

Received: Jun 29, 2020

Revised: Aug 14, 2020

Accepted: Aug 24, 2020

\#These authors contributed equally to this work.

${ }^{*}$ Corresponding author Hyunjung Jung

Swine Science Division,

National Institute of Animal Science,

Rural Development Administration,

Cheonan 31000, Korea.

Tel: +82-41-580-3452

E-mail: hyjjung@korea.kr

Younghwa Kim

Swine Science Division,

National Institute of Animal Science,

Rural Development Administration,

Cheonan 31000, Korea.

Tel: +82-41-580-3446

E-mail: yhkims@korea.kr

Copyright ( 2020 Korean Society of

Animal Sciences and Technology.

This is an Open Access article

distributed under the terms of the

Creative Commons Attribution

Non-Commercial License (http://

creativecommons.org/licenses/by-

$\mathrm{nc} / 4.0 /$ ) which permits unrestricted

non-commercial use, distribution, and

reproduction in any medium, provided

the original work is properly cited.

ORCID

Yongdae Jeong

https://orcid.org/0000-0002-1985-583X

Yohan Choi

https://orcid.org/0000-0003-4710-4731

Doowan Kim

https://orcid.org/0000-0003-2392-5535

\section{Improving behavior characteristics and stress indices of gestating sows housed with group housing facility}

\author{
Yongdae Jeong", Yohan Choi”, Doowan Kim, Joeun Kim, Yejin Min, \\ Hyunjung Jung* and Younghwa Kim*
}

Swine Science Division, National Institute of Animal Science, Rural Development Administration, Cheonan 31000, Korea

\begin{abstract}
This study was conducted to investigate the effects of group-housing facility (GHF), compared to an individual confinement stall (CON), on the reproductive performance, behavior, and stress hormones of gestating sows. A total of 50 primiparous sows (Landrace $\times$ Yorkshire) were randomly allocated into either $\operatorname{CON}(n=25)$ or GHF $(n=25)$ during the gestation period. One week before parturition, the sows were transferred into conventional farrowing crates, and cross-fostering was conducted within $1 \mathrm{~d}$ of delivery. Blood was collected for analyses of stress indices at $75 \mathrm{~d}$ of gestation and postpartum. Reproductive performance was estimated during the period of birth to weaning. Behavior patterns were identified at 90 $\mathrm{d}$ of gestation. Litter size was not different between the CON and GHF treatments. Weaning to estrus interval, however, tended to be lower in the GHF than in the CON $(p<0.1)$. Activity, treating, belly nosing, and exploring behaviors were observed only in the GHF group, whereas rubbing was shown only with the CON. Serum cortisol concentration was lower in the GHF than in the CON at $75 \mathrm{~d}$ of gestation $(p<0.05)$. Sows housed in the GHF showed lower epinephrine and norepinephrine concentrations than those housed in the CON at postpartum $(p<0.05)$. The GHF sows demonstrated more natural behavior characteristics associated with stress relief than the CON sows with no adverse effects on reproductive performance. Therefore, these results suggest that GHF could be applied as an alternative housing facility to improve animal welfare on swine farms.
\end{abstract}

Keywords: Behavior, Gestating sows, Group housing, Stress index

\section{INTRODUCTION}

The swine industry still maintains intensive housing systems in many countries. Particularly, individual confinement stall (CON) has merits in reducing labor intensity, aggression, injury, and space requirements for gestating sows [1-6]. However, this method of production is changing worldwide due to animal welfare considerations that are being legalized in some countries including the European Union and parts of the United States. Additionally, Korea has prohibited the use of gestation stall from 2020. 
Joeun Kim

https://orcid.org/0000-0002-1935-2132

Yejin Min

https://orcid.org/0000-0002-3083-1513

Hyunjung Jung

https://orcid.org/0000-0002-7004-2017

Younghwa Kim

https://orcid.org/0000-0002-9850-8894

Competing interests

No potential conflict of interest relevant to

this article was reported.

Funding sources

This work was carried out with the support

of "Cooperative Research Program for

Agriculture Science and Technology

Development (Project No. PJ01198001)"

Rural Development Administration, Korea.

Acknowledgements

This study was supported by 2020 the RDA

Fellowship Program of National Institute

of Animal Science, Rural Development

Administration, Korea.

Availability of data and material

Upon reasonable request, the datasets

of this study can be available from the

corresponding authors.

Authors' contributions

Conceptualization: Jeong Y, Choi Y, Jung H.

Data curation: Jeong Y, Choi Y, Min Y.

Formal analysis: Choi Y, Kim D.

Methodology: Kim J.

Software: Kim D, Kim J.

Validation: Jung H, Kim Y.

Investigation: Kim D, Kim J, Min Y.

Writing - original draft: Jeong $Y$, Choi $Y$.

Writing - review \& editing: Jung H, Kim Y.

Ethics approval and consent to participate This study was approved by IACUC of Rural Development Administration (No. NIAS2016-163)
Thus, alternative living systems for pregnant sows are needed to address productive performance and welfare concerns.

Group housing systems, as alternatives to CON, are applied widely and have various shapes [6-8]. These shapes are influenced by group housing conditions such as group size, space allowance, or feeding systems including electronic sow feeders and trickle feeders [4,5]. Morgan et al. [8] reported higher lameness and injuries with large group housing (30 sows per group, $9 \mathrm{~m} \times 7 \mathrm{~m}$ ) than with small group housing ( 7 sows per group, $4.5 \mathrm{~m} \times 3.5 \mathrm{~m}$ ) on the first day of the mixing but this receded as the group familiarized. Moreover, they identified that reproductive performance is improved in small and large group housing compared to that in $\mathrm{CON}(0.61 \mathrm{~m} \times 2.2 \mathrm{~m})$ [8]. However, sows housed in CON showed lower culling rates than those subjected to group housing with an electronic sow feeder (20 sows per group) or a trickle feeding system (10 sows per group) because of increased sudden death, non-pregnancy, or failure to feed for group housing [9]. Electronic or trickle feeder in group housing, rather than in rather than CON, increases lameness, skin injuries, and leg problems [4]. These reports indicate sometime bad or good effects of group housing on performance and welfare states in sows. Comparably, many studies demonstrated that reproductive productivity of sows kept in group housing is lower, higher or similar compare to the CON according to previous reviews $[6,10]$. Indeed, group housing systems incur economic costs for the installation or repair of devices or facilities improving sow welfare $[4,5,11,12]$. Thus, it is necessary to review various aspects such as density allowance, group size, and feeder types when employing the group housing concept on a commercial farm [13,14]. Therefore, this study was conducted to investigate reproductive performance and behavior characteristics of gestating sows in a group housing facility (GHF) to determine its potential application as a housing model for swine farms in Korea, in comparison to that with $\mathrm{CON}$.

\section{MATERIALS AND METHODS}

\section{Housing facility preparation}

In a conventional gestation facility, CON was provided as $1.5 \mathrm{~m}^{2}$ area per sow $(0.65 \mathrm{~m} \times 2.3 \mathrm{~m}$, Fig. 1A). The GHF was remodeled to provide $2.4 \mathrm{~m}^{2}$ area per sow $(16.25 \mathrm{~m} \times 3.4 \mathrm{~m}$, Fig. 1B) by removing the lateral bar and extending the rear space of the CON. The $0.4 \mathrm{~m}$ lateral bar on the side of the feeder was retained to avoid interference at feeding time from other sows. The feeder and nipple drinker were retained in the original positions.

\section{Animals, design and management}

Sixty crossbred (Landrace $\times$ Yorkshire) gilts were obtained from the experimental farm of National Institute of Animal Science (NIAS). When onset of estrus was identified, the gilts in the gestating stall were artificially inseminated twice using semen from three Duroc boars. Pregnancy diagnosis was performed via ultrasonography (AV 2100V, Ambisea Tech., Shenzhen, China) at 30 days after mating. Fifty primiparous sows were randomly selected and assigned into two facilities, designated as CON $(n=25)$ and GHF $(n=25)$. The sows were transferred to farrowing crates $(0.65 \mathrm{~m} \times 1.9$ $\mathrm{m})$ at $10 \mathrm{~d}$ before parturition. Cross-fostering was performed to provide 10 or 11 piglets per sow within $1 \mathrm{~d}$ of parturition. The sows used in this study were housed from $30 \mathrm{~d}$ to $105 \mathrm{~d}$ of gestation in either the $\mathrm{CON}$ or GHF.

Experimental diets were prepared based on corn-soybean meal. The nutritional values of feed ingredients used in the diets were cited from our previous studies [15,16] and NRC [17]. The formula and chemical compositions of the experimental diets fed during the gestating and lactating periods are shown as Table 1 . The dietary allocation for gestation was limited to $2.5 \mathrm{~kg}$ from mating to $90 \mathrm{~d}$ 
A

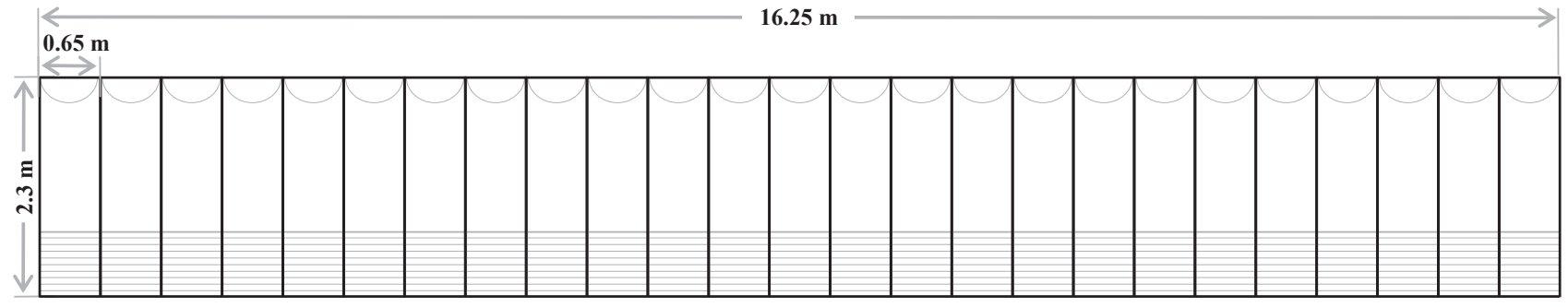

B

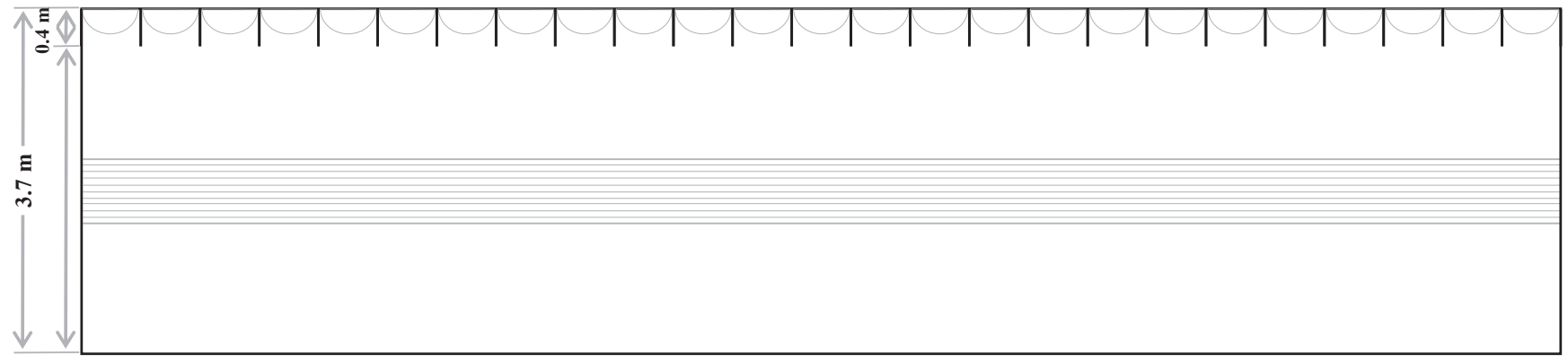

Fig. 1. Design of individual confinement stall (CON) and group housing facility (GHF). (A) CON $(0.65 \mathrm{~m} \times 2.3 \mathrm{~m})$ was side by side in a straight line. (B) GHF $(16.25 \mathrm{~m} \times 3.7 \mathrm{~m})$ was remodeled based on the CON by extending the rear space and by removing the lateral bar, which remained as $0.4 \mathrm{~m}$ of the lateral bar side of the feeder to avoid interference for feeding diets from other sows. White half circles are feeder with nipple for water supply. Straight patterns are the concrete slatted floor.

of gestation, and $2.8 \mathrm{~kg}$ from $90 \mathrm{~d}$ of gestation to parturition; lactating sows, meanwhile, were provided to the diet ad libitum. The gestating and lactating sows were fed at 09:00 and 16:00 h. Water was always available by a nipple drinker for the gestating and lactating periods. Moreover, suckling piglets, from 21 to $28 \mathrm{~d}$ of lactation, were fed to a commercial crumble diet including nutrients such as $4,250 \mathrm{kcal} / \mathrm{kg}$ of gross energy, $23.1 \%$ of crude protein, $0.7 \%$ of calcium, and $0.8 \%$ of available phosphorus. All protocols and experimental animals used in the present study conformed to the guidelines approved and reviewed by the Animal Care and Use Committee of NIAS (No. NIAS2016-163).

\section{Body conditions}

Body weight (BW) and backfat thickness (BFT) of the sows were measured at mating, post-partum, and weaning ( $28 \mathrm{~d}$ of lactation). The BFT was identified at the $10^{\text {th }}$ rib, $6.5 \mathrm{~cm}$ from one side of the back bone using a portable ultrasound device (Loveland, CO, USA). Changes in BW and BFT during gestation and lactation were calculated based on differences between mating and parturition, and between delivery and weaning, respectively.

\section{Reproductive performance}

From post-partum to weaning, piglet numbers per sow were recorded daily to litter size parameters such as total, alive, still born, or dead piglets. At farrowing and during lactation, piglet mortality was calculated as a percentage of live numbers subtracted from total births and from initial suckling size, respectively. Estrus detection in sows was conducted twice-daily by exposing a boar for $10 \mathrm{~min}$ from the last day of lactation. The weaning to estrus interval was obtained based on the difference between weaning and estrus. 
Table 1. Formula and chemical compositions of the experimental diets

\begin{tabular}{|c|c|c|}
\hline Items & Gestation & Lactation \\
\hline Corn & 65.79 & 58.50 \\
\hline Soybean meal & 15.00 & 24.00 \\
\hline Wheat & 6.00 & 4.00 \\
\hline Wheat bran & 2.09 & 3.05 \\
\hline Beet pulp & 5.00 & 5.00 \\
\hline Molasses & 2.00 & 1.50 \\
\hline Limestone & 0.89 & 0.72 \\
\hline Animal fat & 1.00 & 1.03 \\
\hline L-Lysine & 0.12 & 0.07 \\
\hline Mono-calcium phosphate & 1.31 & 1.33 \\
\hline Salt & 0.30 & 0.30 \\
\hline Mineral premix ${ }^{1)}$ & 0.25 & 0.25 \\
\hline Vitamin premix & 0.25 & 0.25 \\
\hline \multicolumn{3}{|l|}{ Calculated compositions } \\
\hline ME (kcal/kg) & 3,300 & 3,300 \\
\hline $\mathrm{CP}(\%)$ & 14.47 & 18.00 \\
\hline Fat (\%) & 3.75 & 3.67 \\
\hline Fiber (\%) & 3.21 & 3.44 \\
\hline $\mathrm{Ca}(\%)$ & 0.83 & 0.80 \\
\hline $\mathrm{P}(\%)$ & 0.62 & 0.67 \\
\hline Lysine (\%) & 0.80 & 1.00 \\
\hline Methionine (\%) & 0.23 & 0.27 \\
\hline
\end{tabular}

1)Provided the following quantities per $\mathrm{kg}$ of complete diet: $\mathrm{Cu}, 87.5 \mathrm{mg}$ as copper sulfate; $\mathrm{Fe}, 125 \mathrm{mg}$ as iron sulfate; I, $1.0 \mathrm{mg}$ as potassium iodate; $\mathrm{Mn}, 75 \mathrm{mg}$ as manganese sulfate; Se, $0.25 \mathrm{mg}$ as sodium selenite; and $\mathrm{Zn}, 60 \mathrm{mg}$ as zinc oxide. ${ }^{2}$ Provided the following quantities per kg of complete diet: vitamin $A, 12,500 \mathrm{IU}$; vitamin $\mathrm{D}_{3}, 1,000 \mathrm{IU}$; vitamin $\mathrm{E}, 125 \mathrm{IU}$; vitamin $\mathrm{K}_{3}, 6.3 \mathrm{mg}$; thiamin, $6.3 \mathrm{mg}$; riboflavin, $25.0 \mathrm{mg}$; pyridoxine, $12.5 \mathrm{mg}$; vitamin $\mathrm{B}_{12}, 0.1 \mathrm{mg}$; pantothenic acid, $100 \mathrm{mg}$; folic acid, 7.5 $\mathrm{mg}$; niacin, $225 \mathrm{mg}$; and biotin, $0.5 \mathrm{mg}$.

$\mathrm{ME}$, metabolizable energy; $\mathrm{CP}$, crude protein.

\section{Behavioral observation}

To distinguish individual, the sows were marked on the head, neck, back, flank, and tail using different color spray (red, yellow, green, blue, and black). Behavior was recorded for $24 \mathrm{~h}$ by using four cameras (YI Action Cam, Xioyi Technology, Shanghai, China) at the $75 \mathrm{~d}$ of gestation. The video filmed was divided and edited into 60 min units using the Vegas Pro ver. 13.0 program (Sony, Tokyo, Japan). To analyze of behavior characteristics, it was extracted to $10 \mathrm{~min}$ of representative image from the dividing videos. Patterns of behavior were categorized as classification described in Table 2 that standing, lying, sitting, eating, rubbing, activity, exploring, threatening, belly nosing, and mounting behaviors. Behavioral characteristics were expressed as duration $(\mathrm{min} / \mathrm{h})$ and frequency (no. of time/h).

\section{Blood collection and analysis}

On $75 \mathrm{~d}$ of gestation and on the day of parturition, $5 \mathrm{ml}$ of blood was collected from the jugular vein of all experimental animals and transferred into a serum separator tube (SSTTM II advance, Becton Dickinson, Oxford, UK). The blood tubes were centrifuged at 3,000 rpm for $20 \mathrm{~min}$ at $4^{\circ} \mathrm{C}$. All serum samples were stored at $-70^{\circ} \mathrm{C}$ before further analysis. Cortisol, epinephrine, and norepinephrine concentrations in the serum were analyzed as stress indices using an automatic blood 
Table 2. Behavior classification of pigs

\begin{tabular}{ll}
\hline \multicolumn{1}{c}{ Behavior names } & \multicolumn{1}{c}{ Description } \\
\hline Standing & Standing with motionless \\
Lying & Ventral and lateral lying \\
Sitting & Front foots upright with hips glued on ground \\
Eating & Act of diet or water intake with putting head into feed hopper, similar action \\
Rubbing & Self-stroking to barn facility \\
Activity & All moving acts such as walking \\
Exploring & Acts as smelling, sucking, chewing of barn facility \\
Threatening & An act of aggressive intent on another pigs \\
Belly nosing & Acts of smelling or pushing on belly of another pigs \\
Mounting & An act of riding over the another pigs \\
\hline
\end{tabular}

analyzer (ADVIA 120, Bayer, Pittsburgh, PA, USA).

\section{Statistical analysis}

Data collected from this study were analyzed by the SAS package (SAS 9.1, SAS Institute, Cary, NC, USA). Basic statistical analyses, comparing the two housing groups, were conducted using the UNIVARIATE procedure. Behavioral data were analyzed by a Kruskal-Wallis test, and the other data were analyzed with a $t$-test. Significance between groups was considered at $p<0.05$.

\section{RESULTS AND DISCUSSION}

Changes in body conditions of sows housed in CON and GHF are shown in Table 3. There were no housing effects on BW and BFT in sows at mating, farrowing, or weaning. Loss of BW and BFT for lactation during lactation was not different between the two housing systems. These results were concurrent with those of Jang et al. [1], who reported no adverse effects on BW and BFT of primiparous sows between group-housing and individual stall at gestation and lactation. Another study reported that the BW of sows during gestation was not different between individual stall and

Table 3. Body conditions of sows kept in individual confinement stall and group housing facility during gestation

\begin{tabular}{lrrr}
\hline \multicolumn{1}{c}{ Items } & CON & GHF & $p$-value \\
\hline Body weight (kg) & & & \\
At the mating (A) & $225.55 \pm 5.00$ & $214.65 \pm 4.30$ & 0.11 \\
At the farrowing (B) & $229.55 \pm 5.48$ & $216.26 \pm 4.38$ & 0.06 \\
At the weaning (C) & $223.27 \pm 5.47$ & $211.47 \pm 4.20$ & 0.09 \\
Change (B-A) & $4.00 \pm 0.97$ & $1.94 \pm 0.51$ & 0.03 \\
Change (C-B) & $-6.28 \pm 0.18$ & $-6.50 \pm 0.25$ & 0.48 \\
Backfat thickness (mm) & & & \\
At the mating (A) & $18.37 \pm 0.19$ & $18.24 \pm 0.20$ & 0.65 \\
At the farrowing (B) & $20.19 \pm 0.21$ & $20.17 \pm 0.17$ & 0.94 \\
At the weaning (C) & $18.13 \pm 0.27$ & $18.09 \pm 0.22$ & 0.90 \\
Change (B-A) & $1.94 \pm 0.11$ & $1.94 \pm 0.13$ & 0.98 \\
Change (C-B) & $-2.06 \pm 0.12$ & $-2.08 \pm 0.15$ & \\
\hline
\end{tabular}

Values are expressed as mean $\pm \mathrm{SE}$.

$\mathrm{CON}$, individual confinement stall; GHF, group housing facility. 
group-housing pen [18]. In the present study, however, change in BW from mating to post-partum was lower in the GHF group than in the CON group (1.94 vs. $4.00 \mathrm{~kg}, p=0.03$ ). The wide rearing area provided to sows induced activity such as walking, which increased their energy requirement $[19,20]$. The diets in this study were supplied to all sows during gestation as $2.5 \mathrm{~kg}$ until $90 \mathrm{~d}$ of pregnancy and at $2.8 \mathrm{~kg}$ before parturition. Moreover, the GHF had a 1.5 -fold increased rearing area than CON (2.4 vs. $1.5 \mathrm{~m}^{2} /$ head). Therefore, low changes of BW in GHF sows could be attributed to an activity increment owing to the extra space.

The reproductive performance of sows housed in CON and GHF groups is shown in Table 4. No differences in total size, alive born, still born animals, and weaned piglets were found between the $\mathrm{CON}$ and GHF groups. Housing type had no effect on the mortality of piglets at farrowing or weaning. However, the interval of weaning to estrus tended to be shorter in the GHF group than in the CON group (4.00 vs $4.35 \mathrm{~d}, p=0.06$ ). Similarly, previous studies reported no effect of group housing on litter size $[2,9,19,21]$. However, Morgan et al. [8] reported that there tended to be higher numbers of total born and alive born piglets from sows subjected to group housing. Chapinal et al. [9] reported higher numbers of weaned piglets in group housing than in individual install for gestation. Generally, the performance of sows kept in group housing is influenced by various factors, such as space allowance, group composition, and floor type. According to reviews of Spoolder et al. [22] and Bench et al. [5], reproductive productivity of group-housed sows is not as good as that in individual stall because of leg injury, aggression, and stress by mixing, group sizes, parities, or feeding types. Furthermore, Jang et al. [1] reported that group-housed sows, as compared to that with individual stall, showed lower tendency of farrowing duration and stillborn piglets, over three consecutive parities. Given these results, further study will be required for comprehensive assessments in the longer-term rather than fragmentary or short-term evaluations.

Behavioral characteristics of gestating sows housed in CON and GHF are presented in Table 5. The duration and frequency of standing was lower in the GHF than in the CON ( 0.77 vs. 10.79 $\min / \mathrm{h}, p=0.01$ and 0.70 vs 5.25 time $/ \mathrm{h}, p=0.01$, respectively). Sitting and eating duration and frequency were slightly lower in the GHF than in the $\mathrm{CON}$, although this was not significant. Sows in the GHF showed a slight increase in lying duration compared to that with CON (44.07 vs. $40.88 \mathrm{~min} / \mathrm{h}$ ), but the frequency did not differ. Rubbing action was observed only in CON. Activity and exploring were identified only in the GHF. The sows housed in the GHF showed only threatening, belly nosing, and mounting actions as mutual interactions. Generally, sows kept in cramped

Table 4. Reproductive performance of sows kept in individual confinement stall and group housing facility during gestation

\begin{tabular}{lrrr}
\hline \multicolumn{1}{c}{ Items } & \multicolumn{1}{c}{ CON } & GHF & $\boldsymbol{p}$-value \\
\hline Litter size (heads/litter) & & & \\
$\quad$ Total born & $12.12 \pm 0.31$ & $12.33 \pm 0.30$ & 0.62 \\
Alive born & $10.96 \pm 0.24$ & $11.23 \pm 0.23$ & 0.42 \\
Still born & $1.08 \pm 0.17$ & $1.22 \pm 0.22$ & 0.62 \\
Actual suckling & $10.65 \pm 0.10$ & $10.63 \pm 0.09$ & 0.86 \\
Weaned & $9.85 \pm 0.15$ & $9.93 \pm 0.15$ & 0.71 \\
Mortality of piglets (\%) & & & \\
Farrowing & $8.61 \pm 1.31$ & $9.43 \pm 1.63$ & 0.70 \\
Weaning & $7.52 \pm 1.37$ & $6.60 \pm 1.19$ & 0.61 \\
Weaning to estrus (d) & $4.35 \pm 0.11$ & $4.00 \pm 0.14$ & 0.06 \\
\hline
\end{tabular}

Values are expressed as mean $\pm \mathrm{SE}$.

$\mathrm{CON}$, individual confinement stall; GHF, group housing facility. 
Table 5. Behavior patterns of sows kept in individual confinement stall and group housing facility during gestation

\begin{tabular}{|c|c|c|c|c|c|c|c|c|}
\hline \multirow{2}{*}{ Items } & \multicolumn{4}{|c|}{ Action duration (min/h) } & \multicolumn{4}{|c|}{ Action frequency (no. of times/h) } \\
\hline & CON & GHF & Z-value & $p$-value & CON & GHF & Z-value & $p$-value \\
\hline Standing & $10.79 \pm 2.23$ & $0.77 \pm 0.44$ & -4.26 & 0.01 & $5.25 \pm 0.99$ & $0.70 \pm 0.36$ & -4.23 & 0.01 \\
\hline Lying & $40.88 \pm 3.15$ & $44.07 \pm 3.35$ & -1.26 & 0.21 & $5.75 \pm 0.36$ & $5.44 \pm 0.44$ & -0.49 & 0.18 \\
\hline Sitting & $0.89 \pm 0.47$ & $0.33 \pm 0.20$ & -1.03 & 0.30 & $0.75 \pm 0.29$ & $0.42 \pm 0.24$ & -1.05 & 0.16 \\
\hline Eating & $5.81 \pm 1.76$ & $5.20 \pm 1.79$ & -0.93 & 0.35 & $2.50 \pm 0.66$ & $1.81 \pm 0.55$ & -1.09 & 0.19 \\
\hline Rubbing & $0.67 \pm 0.44$ & - & - & - & $0.38 \pm 0.21$ & - & - & - \\
\hline Activity & - & $4.27 \pm 1.25$ & - & - & - & $2.37 \pm 0.60$ & - & - \\
\hline Exploring & - & $4.76 \pm 1.42$ & - & - & - & $1.81 \pm 0.58$ & - & - \\
\hline Threatening & - & $0.16 \pm 0.11$ & - & - & - & $0.28 \pm 0.19$ & - & - \\
\hline Belly nosing & - & $0.06 \pm 0.06$ & - & - & - & $0.14 \pm 0.14$ & - & - \\
\hline Mounting & - & $0.36 \pm 0.36$ & - & - & - & $0.14 \pm 0.14$ & - & - \\
\hline
\end{tabular}

Values are expressed as mean $\pm \mathrm{SE}$.

Dashes signified non observation of classified behaviors.

CON, individual confinement stall; GHF, group housing facility.

space allowance showed oral-nasal-facial and sham-chewing actions as stereotypic behaviors, which are continuously repeated movements without motivation $[18,23]$. Behavior is commonly utilized as a welfare index in sows [10]. Zverina et al. [23] reported that standing action is increased in individual stall compared to that in width-adjustable stall, whereas lying is decreased. These behavioral patterns are similar to the results from this study. Furthermore, social and personal interactions as the activity, exploring, threatening, belly-nosing, and mounting were identified only in the GHF sows from the present study. Therefore, the GHF could be induced to enrich the behavioral patterns of gestating sows.

Serum stress indicators of sows housed in CON and GHF are shown in Table 6. Cortisol level was decreased in the GHF compared to that in CON at $75 \mathrm{~d}$ of gestation $(3.50 \mathrm{vs.} 3.78 \mu \mathrm{g} / \mathrm{mL}, p$ $=0.03)$. At postpartum, the GHF showed a tendency to reduce cortisol level compared to those in the CON group ( 3.85 vs. $4.02 \mu \mathrm{g} / \mathrm{mL}, p=0.08$ ). Similarly, epinephrine level at the gestation and post-farrowing stages were decreased in the GHF compared to that in CON (45.28 vs. $47.67 \mathrm{pg}$ / $\mathrm{mL}, p=0.08$ and 45.80 vs. $48.14 \mathrm{pg} / \mathrm{mL}, p=0.04$, respectively). Sows housed in the GHF showed lower norepinephrine levels than those in CON at gestation and postpartum (86.62 vs. $90.38 \mathrm{pg} /$ $\mathrm{mL}, p=0.09$ and 85.33 vs. $91.09 \mathrm{pg} / \mathrm{mL}, p=0.01$, respectively). Conventional narrow-housing sys-

Table 6. Stress indicators of sows kept in individual confinement stall and group housing facility during gestation

\begin{tabular}{lrrr}
\hline \multicolumn{1}{c}{ Items } & \multicolumn{1}{c}{ CON } & \multicolumn{1}{c}{ GHF } & $p$-value \\
\hline At the $75 \mathrm{~d}$ of gestating & & & \\
Cortisol $(\mu \mathrm{g} / \mathrm{mL})$ & $3.78 \pm 0.10$ & $3.50 \pm 0.08$ & 0.03 \\
Epinephrine $(\mathrm{pg} / \mathrm{mL})$ & $47.67 \pm 1.05$ & $45.28 \pm 0.84$ & 0.08 \\
Norepinephrine $(\mathrm{pg} / \mathrm{mL})$ & $90.38 \pm 1.56$ & $86.62 \pm 1.54$ & 0.09 \\
At the farrowing & & & \\
Cortisol $(\mu \mathrm{g} / \mathrm{mL})$ & $4.02 \pm 0.09$ & $3.85 \pm 0.09$ & 0.18 \\
Epinephrine $(\mathrm{pg} / \mathrm{mL})$ & $48.14 \pm 0.87$ & $45.80 \pm 0.75$ & 0.04 \\
Norepinephrine $(\mathrm{pg} / \mathrm{mL})$ & $91.09 \pm 1.14$ & $85.33 \pm 1.55$ & 0.01 \\
\hline
\end{tabular}

Values are expressed as mean \pm SE.

CON, individual confinement stall; GHF, group housing facility. 
tems lead to stress because of the cramped space provided per sow [12,24]. Cortisol, epinephrine, and norepinephrine are effective indicators of stress in pigs [25]. These indices showed a statistical or tendential reduction in the GHF during gestation in this present study. Furthermore, the GHF resulted in lower concentration of epinephrine and norepinephrine at postpartum.

In conclusion, this study indicated that there are no adverse effects on litter performances between CON and GHF housing conditions. However, the GHF improved welfare states by enriching behavior patterns and reducing stress hormones. Therefore, the GHF is a feasible alternative housing systems to the individual stall.

\section{REFERENCES}

1. Jang JC, Hong S, Jin SS, Kim YY. Comparing gestating sows housing between electronic sow feeding system and a conventional stall over three consecutive parities. Livest Sci. 2017;199:3745. https://doi.org/10.1016/j.livsci.2017.02.023

2. Harris MJ, Pajor EA, Sorrells AD, Eicher SD, Richert BT, Marchant-Forde JN. Effects of stall or small group gestation housing on the production, health and behaviour of gilts. Livest Sci. 2006;102:171-9. https://doi.org/10.1016/j.livsci.2005.12.004

3. Choi Y, Min Y, Kim Y, Jeong Y, Kim D, Kim J, et al. Effects of loose farrowing facilities on reproductive performance in primiparous sows.J Anim Sci Technol. 2020;62:218-26. https://doi. org/10.5187/jast.2020.62.2.218

4. Bench CJ, Rioja-Lang FC, Hayne SM, Gonyou HW. Group gestation sow housing with individual feeding - II: how space allowance, group size and composition, and flooring affect sow welfare. Livest Sci. 2013;152:218-27. https://doi.org/10.1016/j.livsci.2012.12.020

5. Bench CJ, Rioja-Lang FC, Hayne SM, Gonyou HW. Group gestation housing with individual feeding - I: how feeding regime, resource allocation, and genetic factors affect sow welfare. Livest Sci. 2013;152:208-17. https://doi.org/10.1016/j.livsci.2012.12.021

6. Salak-Johnson JL. Social status and housing factors affect reproductive performance of pregnant sows in groups. Mol Reprod Dev. 2017;84:905-13. https://doi.org/10.1002/mrd.22846

7. Tuyttens FAM, Van Gansbeke S, Ampe B. Survey among Belgian pig producers about the introduction of group housing systems for gestating sows. J Anim Sci. 2011;89:845-55. https:// doi.org/10.2527/jas.2010-2978

8. Morgan L, Klement E, Novak S, Eliahoo E, Younis A, Sutton GA, et al. Effects of group housing on reproductive performance, lameness, injuries and saliva cortisol in gestating sows. Prev Vet Med. 2018;160:10-7. https://doi.org/10.1016/j.prevetmed.2018.09.026

9. Chapinal N, de la Torre JLR, Cerisuelo A, Gasa J, Baucells MD, Coma J, et al. Evaluation of welfare and productivity in pregnant sows kept in stalls or in 2 different group housing systems. J Vet Behav. 2010;5:82-93. https://doi.org/10.1016/j.jveb.2009.09.046

10. McGlone JJ. Updated scientific evidence on the welfare of gestating sows kept in different housing systems. Prof Anim Sci. 2013;29:189-98. https://doi.org/10.15232/S10807446(15)30224-2

11. Levis D. Housing alternatives for gestating sows and gilts. In: Proceeding of the AD Leman Swine Conference; 2004 Sep 18-21; Minneapolis, MN.

12. Martínez-Miró S, Tecles F, Ramón M, Escribano D, Hernández F, Madrid J, et al. Causes, consequences and biomarkers of stress in swine: an update. BMC Vet Res. 2016;12:171. https://doi.org/10.1186/s12917-016-0791-8

13. Levis DG, Connor L. Group housing systems: choices and designs [Internet]. National Pork Board. 2013 [cited 2020 Aug 3]. https://porkcdn.s3.amazonaws.com/sites/all/files/docu- 
ments/2013SowHousingWebinars/1\%20-\%20Group\%20Housing\%20Systems.Choices\%20 and\%20Designs\%20-03643.pdf

14. Madzingira O. Animal welfare considerations in food-producing animals. In: Abubakar M, Manzoor S, editors. Animal welfare. London, UK: IntechOpen; 2018. p. 99-122.

15. Park S, Cho E, Chung H, Cho K, Sa S, Balasubramanian B, et al. Digestibility of phosphorous in cereals and co-products for animal feed. Saudi J Biol Sci. 2019;26:373-7. https://doi. org/10.1016/j.sjbs.2018.12.003

16. Park SK, Lee YK, Cho ES, Jeong YD. Coefficient of standardized total tract digestibility of phosphorus in oilseed meals and distillers dried grains in growing-finishing pigs. S Afr J Anim Sci. 2017;47:41-8. https://doi.org/10.4314/sajas.v47i1.7

17. NRC [National Research Council]. Nutrient requirements of swine. 11th rev. ed. Washington, DC: National Academy Press; 2012.

18. Hulbert LE, McGlone JJ. Evaluation of drop versus trickle-feeding systems for crated or grouppenned gestating sows. J Anim Sci. 2006;84:1004-14. https://doi.org/10.2527/2006.8441004x

19. Kim KH, Hosseindoust A, Ingale SL, Lee SH, Noh HS, Choi YH, et al. Effects of gestational housing on reproductive performance and behavior of sows with different backfat thickness. Asian-Australas J Anim Sci. 2016;29:142-8. https://doi.org/10.5713/ajas.14.0973

20. Geverink NA, Heetkamp MJW, Schouten WGP, Wiegant VM, Schrama JW. Backtest type and housing condition of pigs influence energy metabolism. J Anim Sci. 2004;82:1227-33. https://doi.org/10.2527/2004.8241227x

21. Karlen GAM, Hemsworth PH, Gonyou HW, Fabrega E, Strom AD, Smits RJ. The welfare of gestating sows in conventional stalls and large groups on deep litter. Appl Anim Behav Sci. 2007;105:87-101. https://doi.org/10.1016/j.applanim.2006.05.014

22. Spoolder HAM, Geudeke MJ, Van der Peet-Schwering CMC, Soede NM. Group housing of sows in early pregnancy: a review of success and risk factors. Livest Sci. 2009;125:1-14. https:// doi.org/10.1016/j.livsci.2009.03.009

23. Zverina LR, Kane J, Crenshaw TD, Salak-Johnson JL. A pilot study: behavior and productivity of gestating sows in width-adjustable stalls. Austin J Vet Sci Anim Husb. 2015;2:1012.

24. Verdon M, Hansen CF, Rault JL, Jongman E, Hansen LU, Plush K, et al. Effects of group housing on sow welfare: a review. J Anim Sci. 2015;93:1999-2017. https://doi.org/10.2527/ jas.2014-8742

25. Smulders D, Verbeke G, Mormède P, Geers R. Validation of a behavioral observation tool to assess pig welfare. Physiol Behav. 2006;89:438-47. https://doi.org/10.1016/j.physbeh.2006.07.002 